\title{
ANÁLISE DO PERFIL LONGITUDINAL E ÍNDICE SL DO RIO ARARANGUÁ (SC) PARA IDENTIFICAÇÃO DE ANOMALIAS ASSOCIADAS A DEFORMAÇÕES NEOTECTÔNICAS E CONTROLES ESTRUTURAIS
}

\author{
Felipe Gomes Rubira $^{(\mathrm{a})}$, Archimedes Perez Filho ${ }^{(\mathrm{b})}$ \\ (a) Departamento de Geografia/Instituto de Geociências, UNICAMP, felipe rubira@ hotmail.com \\ (b) Departamento de Geografia/Instituto de Geociências, UNICAMP, archi@ige.unicamp.br
}

Eixo: SISTEMAS GEOMORFOLÓGICOS: ESTRUTURA, DINÂMICA E PROCESSOS

\begin{abstract}
Resumo
Esta pesquisa objetivou analisar as deformações tectônicas e influências morfoestruturais no arranjo da drenagem do rio Araranguá (SC) por meio da elaboração do perfil longitudinal, aplicação do índice SL de Hack (1973) e identificação de setores anômalos. Assim, os índices, associados a modificações nos padrões de drenagem, disponibilizaram análises tectônicas que forneceram subsídios à interpretação geológica/geomorfológica do rio Araranguá (SC). Os resultados evidenciaram trechos de soerguimento no alto curso, correlacionados a eventos tectônicos deformacionais e as maiores anomalias verificadas ( $1^{\mathrm{a}}$ ordem); setores de subsidência em parte do alto curso e ao longo do médio curso associados a anomalias de $1^{\mathrm{a}}$ ordem, relacionadas ao controle estrutural da Formação Botucatu e Formação Gramado; zonas de agradação no baixo curso, relativas à atuação de diferentes sistemas deposicionais (marinho, eólico, lagunar e fluvial), que em conjunto originaram superfícies planas, marcadas por poucas anomalias de $1^{\mathrm{a}} \mathrm{e} 2^{\mathrm{a}}$ ordem, associadas às desembocaduras de tributários.
\end{abstract}

Palavras chave: Perfil Longitudinal; Índice SL; Anomalias; Neotectônica; Controles Estruturais.

\section{Introdução}

Pesquisas científicas que utilizam a geometria da rede de drenagem como subsídio a análises de processos geomorfológicos regionais e locais tornam-se cada vez mais comuns nos dias atuais. Tais aplicações metodológicas procuram identificar anomalias vinculadas a recentes eventos tectônicos, expressos por movimentos ascensionais de soerguimento ou de subsidência e, ao controle estrutural exercido em função da disposição das falhas e fraturas dos componentes litológicos. Parte desta disseminação metodológica em relação aos processos morfométricos voltados à identificação de anomalias, deve-se a propostas metodológicas elaboradas e aprimoradas por Horton (1945), Strahler (1952), Hack (1973), Bishop (1985), Phillips e Schumm (1987), Schumm (1993).

Neste estudo, destaca-se a aplicação do índice SL de Hack (1973) no rio Araranguá (SC), conhecido na literatura internacional como Stream-Gradient Index ou SL Index (Slope vs. Lenght). Tal índice 
morfométrico foi denominado de Índice Relação Declividade-Extensão (RDE) por Etchebehere et al. (2004), nominação comumente utilizada na literatura brasileira. O objetivo de Hack (1973) ao estabelecer este método consistia na detecção de alterações no perfil longitudinal dos cursos d'água, decorrentes de eventos tectônicos, diferentes resistências à erosão hidráulica do substrato rochoso ou modificações do aporte de carga fluvial, fatores interligados a mudanças de níveis de base locais e regionais dos rios.

Recentes pesquisas brasileiras que elaboraram perfis longitudinais e aplicaram o índice SL em redes de drenagem foram realizadas. Estes estudos apresentaram-se determinantes para interpretações que objetivaram analisar a evolução geomorfológica de complexos sistemas associados a fenômenos tectônicos e, consequentes deformações morfoestruturais. Pode-se citar a aplicação do método em diferentes regiões: bacia hidrográfica do rio do Peixe - SP (ETCHEBEHERE et al., 2004); 26 afluentes da bacia do rio Santo Anastácio-SP (GUEDES et al., 2006); bacia do ribeirão São Pedro-PR (CAMOLEZI et al., 2012); drenagens da zona de falha do rio Alonzo-PR (COUTO et al. 2013); bacia do rio Capivari-MG (MARQUES NETO, PEREZ FILHO, 2013); serra de São Pedro e baixo rio Piracicaba-SP (PINHEIRO E QUEIROZ NETO, 2015).

Com base nestes estudos, esta pesquisa objetiva analisar as deformações tectônicas e influências morfoestruturais no arranjo da drenagem do rio Araranguá (SC), por meio da elaboração do perfil longitudinal, aplicação do índice SL de Hack (1973) e consequente identificação de setores anômalos.

As deformações neotectônicas foram analisadas por meio da identificação de anomalias geomórficas evidenciadas pelo índice SL. As influências morfoestruturais foram avaliadas por meio da integração e relação do substrato rochoso com os ressaltos convexos presentes na morfologia do perfil. Assim, os índices, associados a modificações nos padrões básicos de drenagem, disponibilizaram análises tectônicas que forneceram subsídios à interpretação geológica/geomorfológica da bacia do rio Araranguá.

\section{Metodologia}

\subsection{Perfil Longitudinal}

O perfil longitudinal do rio Araranguá (SC) foi elaborado por meio do software ArcGIS 10.2, objetivando a determinação do gradiente do rio, das áreas em "equilíbrio" (ajustadas) e em "desequilíbrio" (desajustadas), provenientes de setores associados a processos agradacionais e de entalhe do talvegue. Inicialmente, realizou-se a delimitação da bacia hidrográfica através da integração de dados Shuttle Radar Topography Mission (SRTM). Posteriormente, a partir da aquisição das cartas topográficas, foi vetorizado e realizado o merge da rede de drenagem, em conjunto com as isolinhas das curvas de nível com equidistância de 20 metros. A partir da construção da base de dados, iniciou-se o processo de elaboração do perfil longitudinal. Com auxílio do complemento Xtools Pro 10.2 os pontos de intersecção entre a rede 
de drenagem e curvas de nível foram gerados (Xtools Pro $>$ Layer Operations $>$ Create Intersect Points); em seguida, os trechos do rio, entre cada curva de nível, foram segmentados (Xtools Pro $>$ Features Convertion > Split Polylines); com isso, as tabelas de atributos das cotas altimétricas das curvas e das distâncias de cada trecho do rio foram unificadas (Spatial Join one to one).

A partir destes procedimentos a distância total do rio Araranguá e distância de cada trecho segmentado foram calculadas (Calculate geometry $>$ Length $>$ Kilometers). Os dados foram exportados para planilha do excel e o gráfico do Perfil Longitudinal pôde ser elaborado. Utilizou-se gráfico de coordenadas cartesianas do tipo dispersão com linhas suaves. No eixo das ordenadas (x) foram lançadas as cotas altimétricas da nascente a foz $(\mathrm{m})$; no eixo das abscissas (y) foi plotada a extensão do rio $(\mathrm{km})$ com origem posicionada na cabeceira do mesmo. Após estes procedimentos, os dados foram interpolados e deu-se origem a linha de melhor ajuste do perfil, que de modo geral, delimita as áreas em soerguimento ou agradação acima de seu nível e trechos de subsidência abaixo do mesmo.

\section{2. Índice Sl de Hack (1973) e identificação de anomalias}

O índice SL é aplicado a partir da elaboração do perfil longitudinal do rio, em sua totalidade ou em trechos específicos, demarcados por cotas altimétricas pré-definidas em gabinete. Nesta pesquisa ambos os cálculos foram realizados com base em Etchebehere et al. (2004). Para isso, o SL total relacionou a amplitute altimétrica total do rio (cota da nascente e foz) com o logarítimo natural da extensão do curso d'água. O cálculo do SLtrecho foi aplicado em segmentos das drenagens e relacionou a amplitude altimétrica do trecho analisado com a extensão do mesmo em linha reta e em linha sinuosa, que representa o caminho efetivo da drenagem no intervalo da curva de nível analisada. Posteriormente, os índices SLtoтац e SLтRесно foram correlacionados e os setores anômalos foram identificados e classificados a partir de limiares definidos por Seeber e Gornitz (1983).

Os valores que compõem o índice também foram gerados com auxílio do ArcGIS 10.2. Inicialmente calculou-se o índice SL total, sendo obtido pela seguinte fórmula:

$$
\mathrm{SLTOTAL}=\Delta \mathrm{H} / \log \mathrm{L}
$$

Onde, $\Delta \mathrm{H}$ configura-se como a amplitude altimétrica total do rio, a diferença entre cota da nascente e da foz do mesmo; log L apresenta-se como o logaritmo do comprimento total da drenagem, é a projeção horizontal da extensão acumulada do rio.

Posteriormente, calculou-se o índice SL dos trechos, os quais foram aplicados para os segmentos de drenagem definidos pela equidistância das curvas de 20 metros. Foram obtidos pela fórmula:

$$
\mathrm{SL}_{\text {trecho }}=(\Delta \mathrm{H} / \Delta \mathrm{L}) . \mathrm{L}
$$


Onde, $\Delta \mathrm{H}$ representa a amplitude altimétrica entre as curvas de nível $(20 \mathrm{~m}) ; \Delta \mathrm{L}$ retrata a medida em linha reta da distância entre as duas curvas analisadas; L simboliza o caminho efetivo da drenagem no intervalo de cada curva de nível. A partir da obtenção destes dados executaram-se os cálculos. Após a obtenção do índice SL total e dos trechos, realizou-se procedimentos necessários para a identificação das anomalias:

$$
\text { Anomalias }=\text { SLTrecho } / \text { SLTOTAL }
$$

Deste modo, os setores anômalos foram identificados e classificados a partir de limiares definidos por Seeber e Gornitz (1983). Tais autores consideram SLтвесно / SLtoтаL = 2 como o limiar inferior da faixa de anomalias; $\geq 2$ e $<10$ como anomalia de segunda ordem e $\geq 10$ como anomalias de primeira ordem. Tais anomalias representam desajustes na concavidade natural do perfil longitudinal.

Os valores adquiridos foram inseridos em planilhas do excel e as operações matemáticas foram realizadas. Por fim, os dados foram adicionados ao gráfico do perfil longitudinal e a curva de melhor ajuste. Os valores finais do índice SL de cada trecho foram plotados em forma de nova série de dados, como linha secundária, esta ação possibilitou a inserção do traçado contínuo das curvas de isovalores do índice no gráfico, em conjunto com o traçado do perfil longitudinal.

\section{Contexto Geológico e Geomorfológico local}

A área de estudo está localizada no litoral sul do Estado de Santa Catarina e corresponde a bacia hidrográfica do rio Araranguá (Figura 1). O rio Araranguá (SC) percorre ao longo de seu trajeto quatro compartimentos geológico-geomorfológicos, dispostos na bacia hidrográfica homônima. De oeste para leste: Encostas da Serra Geral; Contrafortes da Serra Geral; Serras do Leste Catarinense e Planície Costeira. Estes compartimentos se alternam em curta extensão da nascente até a foz do rio, produzindo desníveis acentuados, de mais de 1000 metros de altitude em 60 km de extensão (Figura 1), os quais serão identificados e avaliados pelo índice SL (ADAMI e CUNHA, 2011).

A nascente e o alto curso do rio Araranguá localizam-se na escarpa da Serra Geral, constituída por rochas

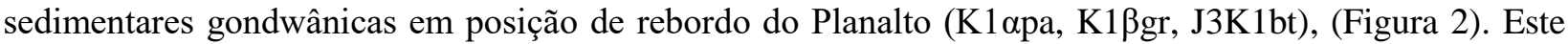
compartimento corresponde à área mais elevada da bacia, onde se localizam a maioria das nascentes e dos divisores de água a oeste, abrange elevação correspondente a 600 e 1200 metros de altitude. Os rios entalham e recortam o front da escarpa do Planalto, elaborando vales fluviais encaixados e profundos em forma de "V", muitas vezes delineados por condicionantes estruturais do substrato rochoso. Observa-se a presença de cachoeiras vinculada às mudanças no nível de base por deformações neotectônicas, vazões acentuadas em função da declividade e cascalheiras no leito do rio Araranguá, vinculadas ao processo de erosão responsável pelo recuo da escarpa (DANTAS et al., 2005; ADAMI e CUNHA, 2011). 


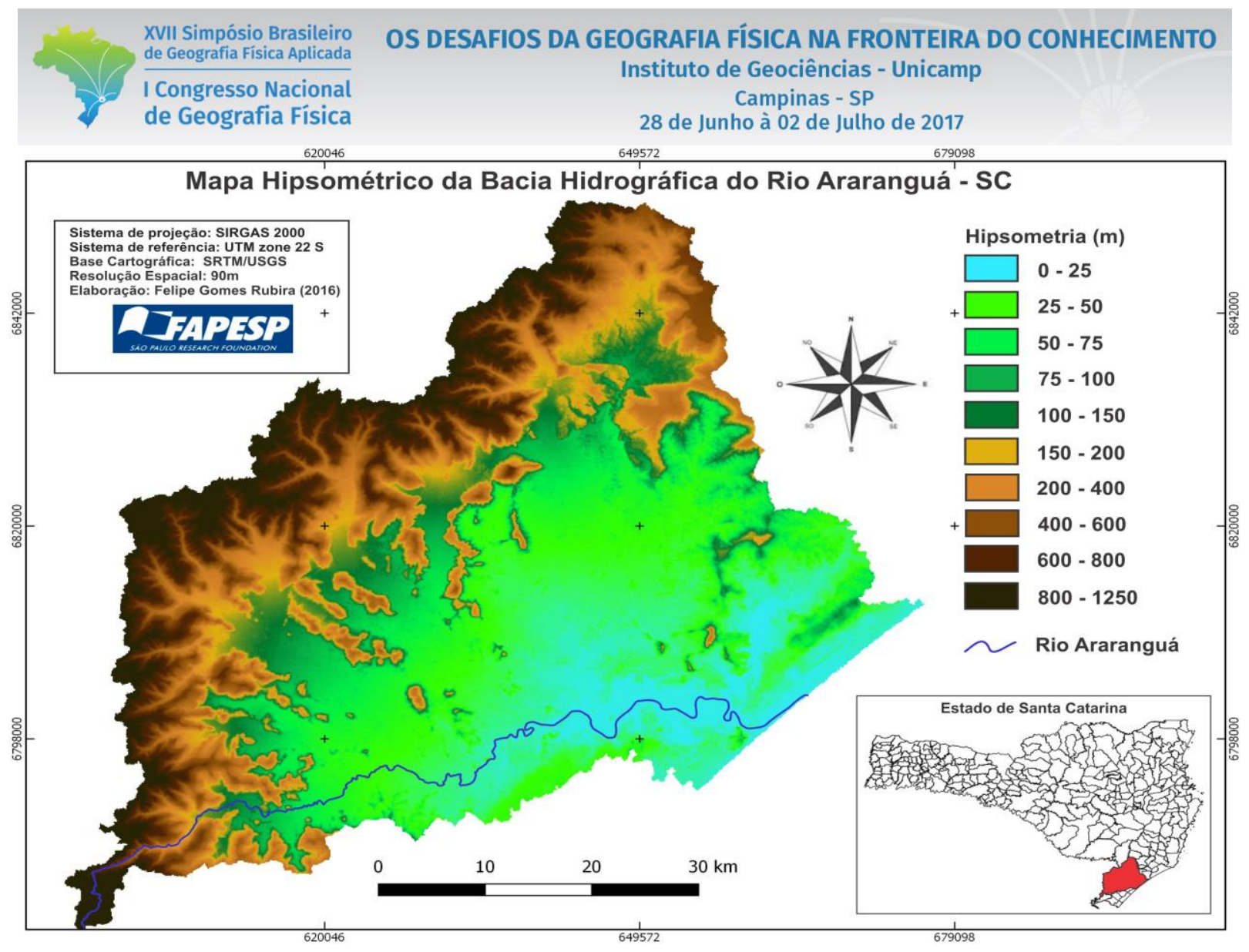

Figura 1- Mapa hipsométrico da bacia do rio Araranguá (SC) e localização da área de estudo

O compartimento Contrafortes da Serra Geral é disposto pelas planícies de leques aluviais constituídas de depósitos culuvio-aluvionares (Q2ca) de idade plio-pleistocênica da baixada litorânea sul-catarinense (Figura 2). A erosão da borda do planalto em climas pretéritos, mais secos que o atual, originou um conjunto de morros e colinas a sua frente, que se estendem sobre o compartimento da Planície Costeira e formam os divisores entre afluentes do rio Araranguá (P3T1rr, P3t).

Possui gênese atrelada às mudanças do nível de base e a constantes reajustes do curso d'água, vinculados a retomadas erosivas da escarpa do planalto com consequente deposição espraiada, capaz de desenvolver os leques aluviais sobre o conjunto de morros e colinas. Esta dinâmica erosiva/deposicional originou formas de relevo alongadas e irregulares, com disposição noroeste-sudeste, assentadas sobre a planície do médio curso do rio Araranguá, entre 600 e 200 metros (DANTAS et al., 2005; ADAMI e CUNHA, 2011). O Compartimento Serra do Leste é composto pela Bacia Carbonífera Sul-Catarinense, constituída por rochas sedimentares gondwânicas (P1rb, P1p) e, em parte, por sills de diabásio (K1ßsg), constituindo-se os materiais mais antigos da bacia hidrográfica (Figura 2). Apresenta relevo bem dissecado, com vales profundos e encostas íngremes. É o único dos quatro compartimentos da bacia hidrográfica que não está presente ao longo do curso do rio Araranguá (DANTAS et al., 2005; ADAMI e CUNHA, 2011). 


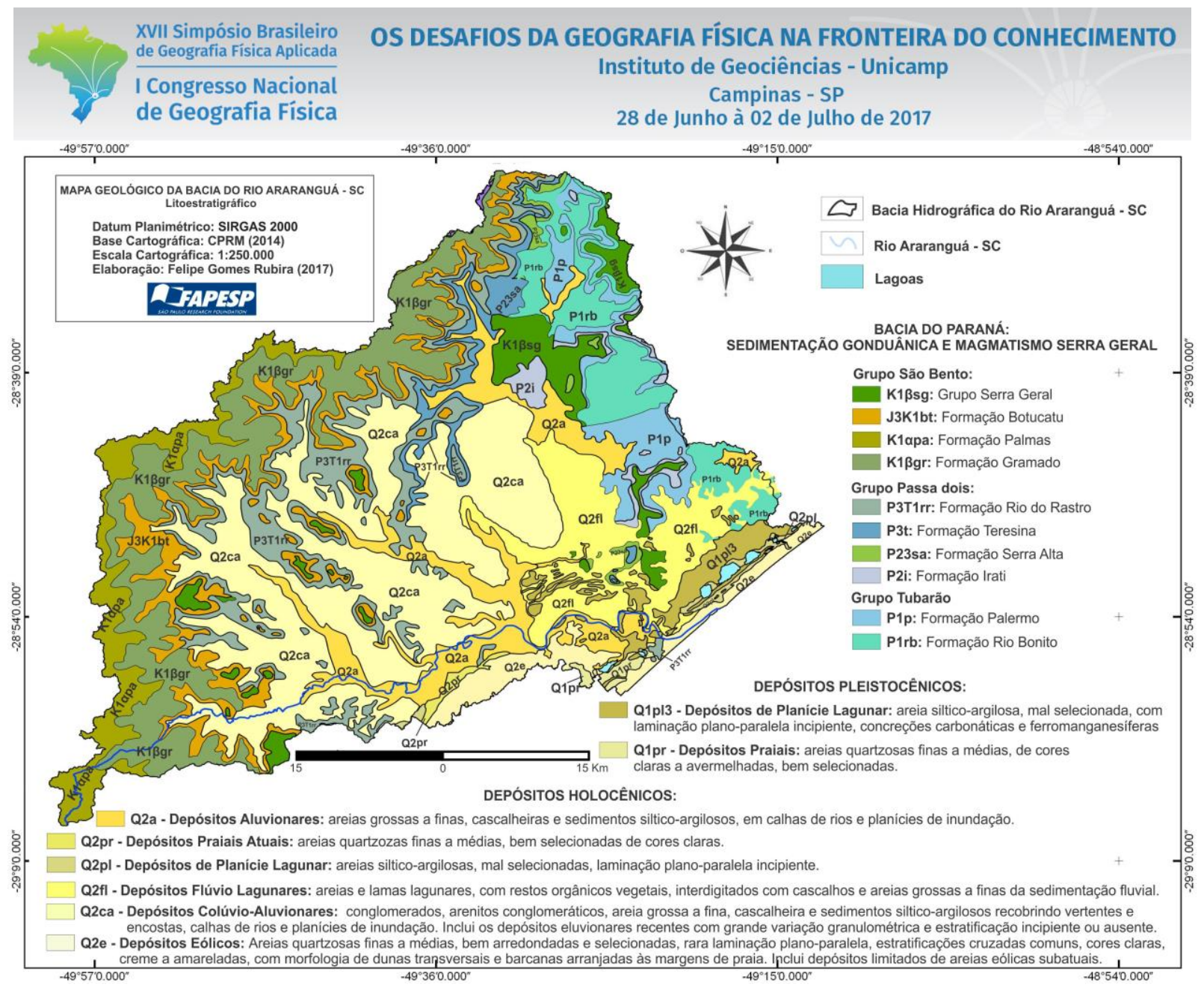

Figura 2 - Mapa geológico da bacia do rio Araranguá (SC)

Por fim, o Compartimento Planície Costeira, onde se insere o baixo curso e foz do rio Araranguá, é constituído por: depósitos marinhos (Q1pr, Q2pr), com gênese atrelada a movimentos eustáticos, vinculados às oscilações climáticas pleistocênicas e pulsações climáticas holocênicas; depósitos lagunares provenientes da sedimentação de antigas lagoas (Q1pl3, Q2pl, Q2fl); depósitos fluviais (Q2a, Q2fl) e eólicos (Q2e). Tal compartimento inicia-se a 200m e se encerra no contato das dunas e das praias atuais a 0 metros de altitude, caracterizando um declive suave praticamente em toda a área central da bacia. $\mathrm{O}$ trecho do rio disposto neste compartimento também se caracteriza por alto volume de seixos de tamanhos variados, provenientes das encostas da Serra Geral, transportados tanto por ação gravitacional (rolados) quanto por transporte fluvial (DANTAS et al., 2005; ADAMI e CUNHA, 2011).

\section{Resultados e Discussão}

O início da morfologia do perfil longitudinal do rio indica trechos de soerguimento no alto curso, observase mudança abrupta na geometria da linha, a qual caracteriza alteração subta de declividade relacionada a 


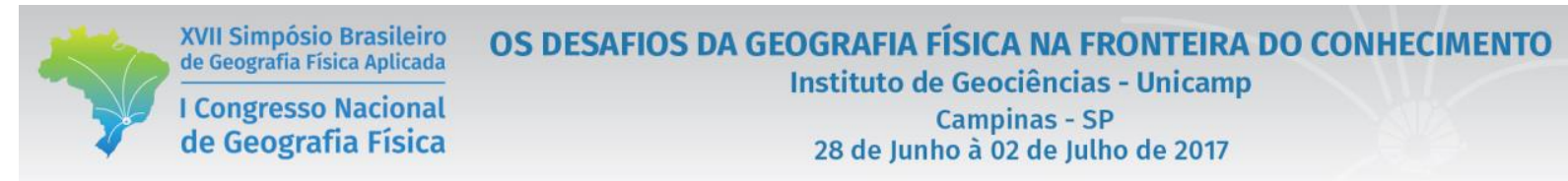

escarpas do Planalto de Santa Catarina (Figura 3). O segmento mensurado (quilômetro 2 ao 8) possivelmente está relacionado a deformações neotectônicas, rupturas geológicas responsáveis por elaborar desníveis altimétricos inerentes ao compartimento geomorfológico da Serra Geral e, por promulgar encaixoeramentos em função das anomalias geradas.

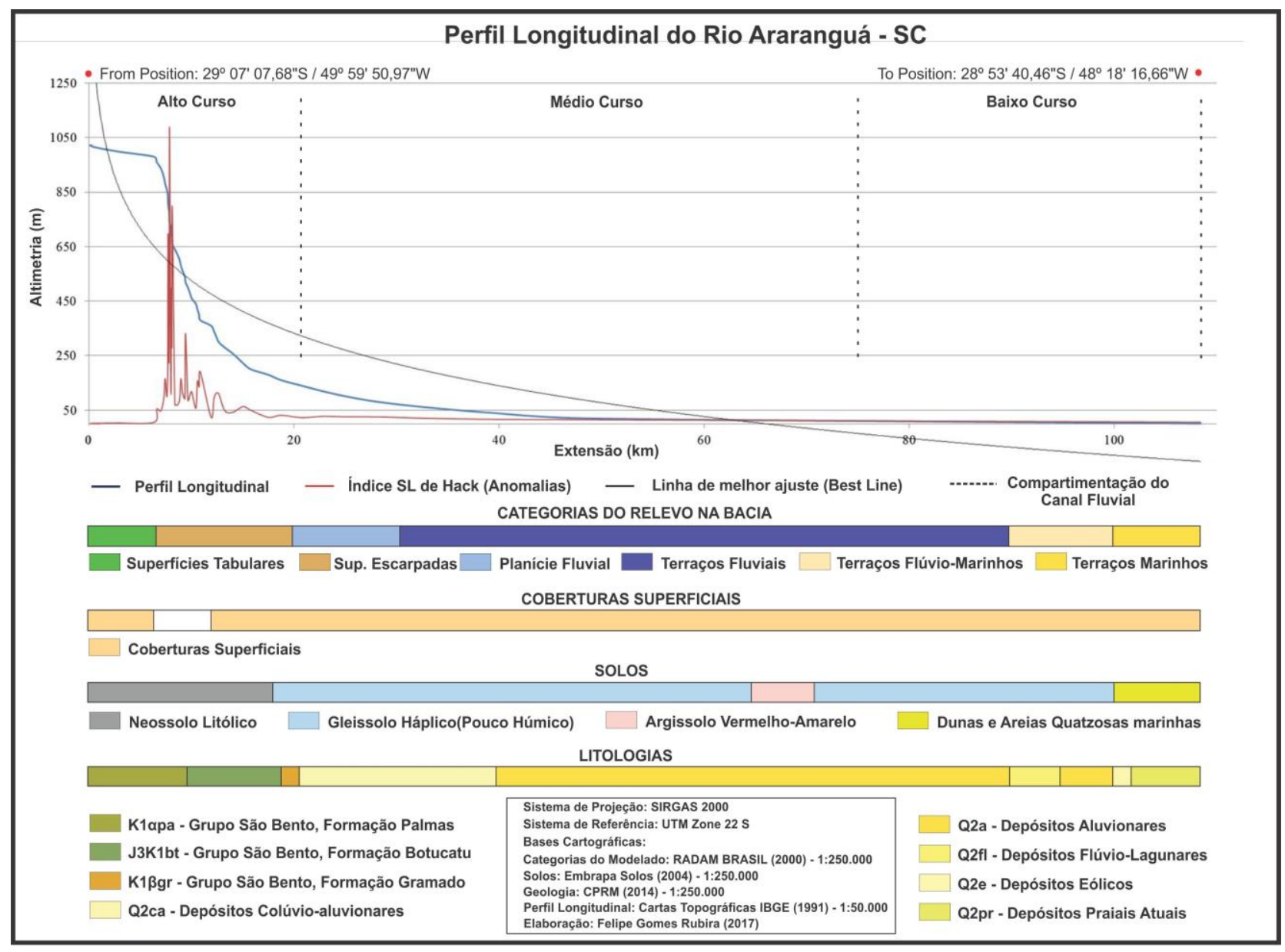

Figura 3: Perfil Longitudinal, Índice SL de Hack, linha de melhor ajuste e compartimentação do canal do rio Araranguá (SC) com respectivas litologias, formações pedológicas e coberturas superficiais adjacentes.

Ao observar a disposição da curva de melhor ajuste, torna-se possível correlacionar os desajustes com mudanças de nível de base, possivelmente elaboradas em função de eventos neotectônicos. Na tentativa de regularizar seu perfil, o rio, impulsionado pelo elevado gradiente e vazões acentuadas em função da alta declividade, promove o entalhamento do talvegue, recorte e recuo do front da escarpa. Controles estruturais, por meio do pirateamento de águas de canais localizados no topo do planalto também são observados na morfologia do perfil. Cotuvelos de drenagem corroboram para tal afirmação. 
Em um segundo momento, ainda no alto curso (quilômetro 8 ao 21), extendendo-se em direção a parte final do médio curso (quilômetro 21 ao 62), observa-se consideravel trecho do perfil em subsidência, correspondente a curva parabólica côncava com declividades maiores em direção à nascente. A subsidência em questão relaciona-se com as mudanças de nivel de base verificadas entre 1000 e 600 metros de altitude, na escapa do planato, suscitadas em função de eventos neotectônicos de ascensão. Tais deformações levam a corrente a se ajustar em busca de um novo equilíbrio, erodindo o próprio leito do rio. Esta incisão acelerada do talvegue, na tentativa de suavizar o perfil, provavelmente foi a responsável por originar o trecho em subsidência homônimo.

Assim, o rio, instalado nas linhas de fraqueza dos arenitos (controle estrutural) promove acentuada retomada erosiva da escarpa do planalto, proporcionada pelo elevado gradiente e alta vazão do trecho em questão, capazes de desenvolver leques aluviais sobre o conjunto de morros e colinas que se estendem no compartimento da Planície Costeira. Salienta-se que este segmento é caracterizado por forte controle estrutural, capaz de direcionar o rio por entre as falhas e fraturas litológicas identificadas na Formação Botucatu e Formação Gramado, dispostas no compartimento geomorfológico Contrafortes da Serra Geral. Em um terceiro momento, relacionado ao fim do médio curso (quilômetro 62 ao 74) e ao longo de todo baixo curso (quilômetro 74 ao 108), nota-se a formação de zona agradacional, o perfil longitudinal do rio associado a linha de melhor ajuste deflagram tal processo. Esta porção do perfil longitudinal evidencia a atuação de diferentes sistemas deposicionais, que em conjunto elaboram superfícies planas, com declives suaves, associadas ao compartimento da Planície Costeira.

Por meio de trabalhos de campo, observou-se a deposição de expessos pacotes de materiais inconsolidados na plataforma agradacional, associados a sedimentos provenientes de depósitos fluviais, eólicos e marinhos. Também se verificou elevado volume de seixos de tamanhos variados, materiais alóctones associados ao recuo da escarpa do planalto, transportados por ação gravitacional (rolados) e transporte fluvial (depósitos colúvio-aluvionares).

Grande parte destes materiais inconsolidados, dispostos nas superfícies deste trecho, referem-se às areias marinhas, as quais possivelmente possuem gênese atrelada a movimentos eustáticos promovidos por pulsações climáticas holocênicas, responsáveis por depositar espessos mantos de sedimentos marinhos na foz do rio durante episódios regressivos do nível relativo do mar. Tal interpretação é baseada na curva de ajuste, que se distancia da morfologia do perfil (linha) conforme se aproxima da desembocadura no oceano Atlântico, área com expressiva ocorrência de depósitos marinhos dispostos sobre as superfícies aplainadas dos terraços flúviomarinhos e marinhos. 
Verificam-se poucos trechos do rio em equilíbrio, o qual, a procura de seu constante ajuste, origina setores que atualmente evidenciam processos relacionados a soerguimento (alto curso), subsidência (médio curso) e agradação (baixo curso).

No sentido de prever os ajustes do rio em busca da regularização do perfil, pressupõe que o mesmo continue erodindo o front da escarpa até suavizar as declividades da mesma. Os materiais provenientes do acelerado processo erosivo nas áreas escarpadas tenderiam a ser depositados no trecho em subsidência, o que elevaria a ocorrência de detritos rolados e intensificaria a formação de leques aluviais. Para completar o perfeito ajuste, o rio propenderia a eliminar parte dos sedimentos dispostos na zona de agradação do baixo curso por meio do transporte de parte dos depósitos para o oceano Atlântico. Dinâmica que completaria, teoricamente, o perfeito equilíbrio do perfil, como aponta a best line.

Salienta-se, que a análise do parágrafo anterior, apresenta caráter puramente hipotético dedutivista, porque, ao longo destes processos de reajuste, muito provavelmente ocorreriam pulsações climáticas e novos processos de alterações crustais. Estes fenômenos promoveriam distúrbios no sistema e suscitariam novas mudanças de nível de base que, alterariam toda a dinâmica erosiva/deposicional fluvial, pois, obrigariam o rio a procurar novos mecanismos associados a constante busca de equilíbrio, modelo classificado como ideal, porém praticamente irreal e de rara ocorrência geomorfológica.

Para representar de maneira empírica a disposição das anomalias, o índice SL de Hack (1973) foi aplicado em todos os trechos do rio (Tabela1). Os resultados obtidos confirmam o que se visualizou no perfil longitudinal do rio Araranguá. Os valores baixos representam setores mais suaves e bem ajustados do canal fluvial em relação ao perfil longitudinal, baixo gradiente e pequena competência erosiva. Em oposição, os valores elevados estão associados a trechos do curso d'água onde a relação declividade extensão é acentuada, representando segmentos íngremes e desajustados em relação ao perfil longitudinal, com alto gradiente e elevado potencial erosivo. Estes valores foram essenciais para a identificação de setores anômalos do rio, sendo classificados a partir de limiares definidos por Seeber e Gornitz (1983). Correlaciona-se os baixos valores a declividades suaves da cabeceira do rio, localizada ainda no planalto de Santa Catarina, esta predisposição foi confirmada pelos índices deflagrados entre a nascente e o trecho 1. Ao aproximar da escarpa do planalto os valores do índice apontam para anomalias de $2^{\mathrm{a}}$ ordem, caracterizadas pelo trecho 2 e 3 (correspondente ao quilômetro 2 ao 6), possivelmente relacionadas ao entalhe do talvegue, motivado por retomadas erosivas e por débitos relacionados a chuvas torrenciais de alta energia. 
XVII Simpósio Brasileiro de Geografia Fisica Aplicada I Congresso Nacional de Geografia Física
OS DESAFIOS DA GEOGRAFIA FÍSICA NA FRONTEIRA DO CONHECIMENTO

Instituto de Geociências - Unicamp

Campinas - SP

28 de Junho à 02 de Julho de 2017

Tabela I - Valores dos cálculos

\begin{tabular}{|c|c|c|c|c|c|c|c|c|c|}
\hline Thechos & $\begin{array}{l}\text { Altitude } \\
\text { curvas } \\
(\mathbf{m})\end{array}$ & $\begin{array}{c}\text { Amplitude } \\
\text { das curvas } \\
(\Delta \mathrm{H})\end{array}$ & $\begin{array}{c}\Delta \mathbf{L} \\
\text { (trecho) }\end{array}$ & $\begin{array}{c}\mathbf{L} \\
\text { (trecho) }\end{array}$ & $\begin{array}{c}\mathbf{L} \\
\text { (total) }\end{array}$ & $\begin{array}{c}\text { SL dos } \\
\text { trechos } \\
(\Delta \mathbf{h} / \Delta \mathrm{l}) * \mathrm{~L}\end{array}$ & $\begin{array}{c}\text { SLtotal } \\
(\Delta \mathbf{h} / \operatorname{logL})\end{array}$ & $\begin{array}{l}\text { SLtrecho/ } \\
\text { SLtotal }\end{array}$ & $\begin{array}{c}\text { Ordem } \\
\text { das } \\
\text { anomalias }\end{array}$ \\
\hline Nascente & 1037 & 0 & 0 & 0 & 0 & 0 & 0 & 0 & 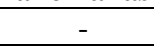 \\
\hline Trecho 1 & 1020 & 17 & 0,196767 & 0,196 & 0,196 & 16,93373381 & 9,56 & 1,770710086 & - \\
\hline Trecho 2 & 1000 & 20 & 1,85343 & 2,493 & 2,689 & 29,01647216 & 9,56 & 3,034166032 & $2^{\mathrm{a}}$ ordem \\
\hline Trecho 3 & 980 & 20 & 2,358763 & 3,663 & 6,352 & 53,85873867 & 9,56 & 5,631847817 & $2^{\mathrm{a}}$ ordem \\
\hline Trecho 4 & 960 & 20 & 0,257848 & 0,276 & 6,628 & 514,101331 & 9,56 & 53,75804429 & $1^{\mathrm{a}}$ ordem \\
\hline Trecho 5 & 940 & 20 & 0,312694 & 0,363 & 6,991 & 447,1464115 & 9,56 & 46,75676787 & $1^{\mathrm{a}}$ ordem \\
\hline Trecho 6 & 920 & 20 & 0,21562 & 0,22 & 7,211 & 668,8618867 & 9,56 & 69,94089445 & $1^{\mathrm{a}}$ ordem \\
\hline Trecho 7 & 900 & 20 & 0,142704 & 0,142 & 7,353 & 1030,524723 & 9,56 & 107,7588995 & $1^{\mathrm{a}}$ ordem \\
\hline Trecho 8 & 880 & 20 & 0,093812 & 0,096 & 7,449 & 1588,069757 & 9,56 & 166,0597224 & $1^{\mathrm{a}}$ ordem \\
\hline Trecho 9 & 860 & 20 & 0,161132 & 0,165 & 7,614 & 945,0636745 & 9,56 & 98,82249239 & $1^{\mathrm{a}}$ ordem \\
\hline Trecho 10 & 840 & 20 & 0,085031 & 0,087 & 7,701 & 1811,339394 & 9,56 & 189,4063631 & $1^{\mathrm{a}}$ ordem \\
\hline Trecho 11 & 820 & 20 & 0,023333 & 0,024 & 7,725 & 6621,523165 & 9,56 & 692,3929468 & $1^{\mathrm{a}}$ ordem \\
\hline Trecho 12 & 800 & 20 & 0,024868 & 0,027 & 7,752 & 6234,518256 & 9,56 & 651,9249968 & $1^{\mathrm{a}}$ ordem \\
\hline Trecho 13 & 780 & 20 & 0,072442 & 0,073 & 7,825 & 2160,348969 & 9,56 & 225,9012544 & $1^{\mathrm{a}}$ ordem \\
\hline Trecho 14 & 760 & 20 & 0,035989 & 0,036 & 7,861 & 4368,557059 & 9,56 & 456,8069945 & $1^{\mathrm{a}}$ ordem \\
\hline Trecho 15 & 740 & 20 & 0,015188 & 0,015 & 7,876 & 10371,3458 & 9,56 & 1084,86881 & $1^{\mathrm{a}}$ ordem \\
\hline Trecho 16 & 720 & 20 & 0,136489 & 0,141 & 8,017 & 1174,746683 & 9,56 & 122,8397602 & $1^{\mathrm{a}}$ ordem \\
\hline Trecho 17 & 700 & 20 & 0,034048 & 0,034 & 8,051 & 4729,205827 & 9,56 & 494,5189615 & $1^{\mathrm{a}}$ ordem \\
\hline Trecho 18 & 680 & 20 & 0,059602 & 0,06 & 8,111 & 2721,720748 & 9,56 & 284,6022285 & $1^{\mathrm{a}}$ ordem \\
\hline Trecho 19 & 660 & 20 & 0,021323 & 0,021 & 8,132 & 7627,444543 & 9,56 & 797,579148 & $1^{\mathrm{a}}$ ordem \\
\hline Trecho 20 & 640 & 20 & 0,24774 & 0,267 & 8,399 & 678,0495681 & 9,56 & 70,90162292 & $1^{\mathrm{a}}$ ordem \\
\hline Trecho 21 & 620 & 20 & 0,262345 & 0,263 & 8,662 & 660,3518268 & 9,56 & 69,05102284 & $1^{\mathrm{a}}$ ordem \\
\hline Trecho 22 & 600 & 20 & 0,203369 & 0,205 & 8,867 & 872,0109751 & 9,56 & 91,18358929 & $1^{\mathrm{a}}$ ordem \\
\hline Trecho 23 & 580 & 20 & 0,113256 & 0,114 & 8,981 & 1585,964541 & 9,56 & 165,8395862 & $1^{\mathrm{a}}$ ordem \\
\hline Trecho 24 & 560 & 20 & 0,174226 & 0,175 & 9,156 & 1051,048638 & 9,56 & 109,9050242 & $1^{\mathrm{a}}$ ordem \\
\hline Trecho 25 & 540 & 20 & 0,210277 & 0,217 & 9,373 & 891,4907479 & 9,56 & 93,22053109 & $1^{\mathrm{a}}$ ordem \\
\hline Trecho 26 & 520 & 20 & 0,059577 & 0,06 & 9,433 & 3166,658274 & 9,56 & 331,1280199 & $1^{\mathrm{a}}$ ordem \\
\hline Trecho 27 & 500 & 20 & 0,23365 & 0,236 & 9,669 & 827,6481917 & 9,56 & 86,54470523 & $1^{\mathrm{a}}$ ordem \\
\hline Trecho 28 & 480 & 20 & 0,195864 & 0,196 & 9,865 & 1007,331618 & 9,56 & 105,3336657 & $1^{\mathrm{a}}$ ordem \\
\hline Trecho 29 & 460 & 20 & 0,17968 & 0,18 & 10,045 & 1118,098842 & 9,56 & 116,9162643 & $1^{\mathrm{a}}$ ordem \\
\hline Trecho 30 & 440 & 20 & 0,379283 & 0,403 & 10,448 & 550,9342628 & 9,56 & 57,60955422 & $1^{\mathrm{a}}$ ordem \\
\hline Trecho 31 & 420 & 20 & 0,141681 & 0,143 & 10,591 & 1495,048736 & 9,56 & 156,3327915 & $1^{\mathrm{a}}$ ordem \\
\hline Trecho 32 & 400 & 20 & 0,166272 & 0,171 & 10,762 & 1294,505389 & 9,56 & 135,3625712 & $1^{\mathrm{a}}$ ordem \\
\hline Trecho 33 & 380 & 20 & 0,12002 & 0121 & 10,883 & 1813,531078 & 9,56 & 189,635541 & $1^{\mathrm{a}}$ ordem \\
\hline Trecho 34 & 360 & 20 & 1,023989 & 1,042 & 11,925 & 232,9126582 & 9,56 & 24,35498265 & $1^{\mathrm{a}}$ ordem \\
\hline Trecho 35 & 340 & 20 & 0,275664 & 0,279 & 12,204 & 885,4257357 & 9,56 & 92,58633083 & $1^{\mathrm{a}}$ ordem \\
\hline Trecho 36 & 320 & 20 & 0,229928 & 0,231 & 12,435 & 1081,642949 & 9,56 & 113,1041802 & $1^{\mathrm{a}}$ ordem \\
\hline Trecho 37 & 300 & 20 & 0,239382 & 0,24 & 12,675 & 1058,976865 & 9,56 & 110,7340553 & $1^{\text {a }}$ ordem \\
\hline Trecho 38 & 280 & 20 & 0,569934 & 0,582 & 13,257 & 465,2117614 & 9,56 & 48,64580767 & $1^{\mathrm{a}}$ ordem \\
\hline Trecho 39 & 260 & 20 & 0,705147 & 0,714 & 13,971 & 396,2578016 & 9,56 & 41,43549756 & $1^{\mathrm{a}}$ ordem \\
\hline Trecho 40 & 240 & 20 & 0,568899 & 0.586 & 14,557 & 511,7604355 & 9,56 & 53,51326382 & $1^{\mathrm{a}}$ ordem \\
\hline Trecho 41 & 220 & 20 & 0,496244 & 0,563 & 15,12 & 609,3776449 & 9,56 & 63,72080453 & $1^{\mathrm{a}}$ ordem \\
\hline Trecho 42 & 200 & 20 & 0,667941 & 0,698 & 15,818 & 473,6346474 & 9,56 & 49,52656376 & $1^{\mathrm{a}}$ ordem \\
\hline Trecho 43 & 180 & 20 & 1,522523 & 1,683 & 17,501 & 229,8947208 & 9,56 & 24,03940593 & $1^{\mathrm{a}}$ ordem \\
\hline Trecho 44 & 160 & 20 & 1,252693 & 1,279 & 18,78 & 299,8340375 & 9,56 & 31,35275188 & $1^{\mathrm{a}}$ ordem \\
\hline Trecho 45 & 140 & 20 & 1,903504 & 1,986 & 20,766 & 218,1870908 & 9,56 & 22,81517394 & $1^{\mathrm{a}}$ ordem \\
\hline Trecho 46 & 120 & 20 & 1,737773 & 2,026 & 22,792 & 262,3127417 & 9,56 & 27,42926177 & $1^{\mathrm{a}}$ ordem \\
\hline Trecho 47 & 100 & 20 & 2,034432 & 2,392 & 25,184 & 247,5777023 & 9,56 & 25,88846261 & $1^{\mathrm{a}}$ ordem \\
\hline Trecho 48 & 80 & 20 & 2,33785 & 3,145 & 28,329 & 242,3508779 & 9,56 & 25,34190916 & $1^{\mathrm{a}}$ ordem \\
\hline Trecho 49 & 60 & 20 & 3,398521 & 4,731 & 33,06 & 194,5552198 & 9,56 & 20,3440596 & $1^{\mathrm{a}}$ ordem \\
\hline Trecho 50 & 40 & 20 & 4,996581 & 6,383 & 39,443 & 157,8799583 & 9,56 & 16,5090368 & $1^{\mathrm{a}}$ ordem \\
\hline Trecho 51 & 20 & 20 & 6,746993 & 9,234 & 48,677 & 144,2924278 & 9,56 & 15,08822921 & $1^{\mathrm{a}}$ ordem \\
\hline Trecho 52 & 0 & 20 & 37,89832 & 59,759 & 108,436 & 57,2247002 & 9,56 & 5,983816384 & $2^{\mathrm{a}}$ ordem \\
\hline
\end{tabular}




\section{OS DESAFIOS DA GEOGRAFIA FÍSICA NA FRONTEIRA DO CONHECIMENTO \\ Instituto de Geociências - Unicamp \\ Campinas - SP \\ 28 de Junho à 02 de Julho de 2017}

$\mathrm{Na}$ faixa altimétrica entre 960 e 660 metros (correspondente ao quilômetro 6 ao 8), correlata a área em soerguimento no perfil, observa-se alteração abrupta da energia da corrente em conjunto com o potencial erosivo, que se intensifica. A área homônima insere-se entre os trechos 4 e 19 e associa-se a escarpa do planalto de Santa Catarina. Nesta porção do perfil longitudinal localizam-se as maiores anomalias verificadas. Altos valores do índice, relacionados às deformações crustais de $1^{\mathrm{a}}$ ordem podem ser observados.

Estas anomalias indicam mudanças abruptas em sequência, vinculadas a diversos encachoeiramentos, possivelmente relacionados a recentes eventos tectônicos deformacionais. Rupturas de declive e mudanças do nível de base, representadas pelos ressaltos convexos identificados no perfil longitudinal, associadas aos picos da linha do índice SL, evidenciadas empiricamente pelos valores dos índices aplicados, ilustram as anomalias, que atingem expressivos números, até 1084,86, referente ao trecho 15 (representado pelo maior pico da linha SL no perfil).

$\mathrm{Na}$ faixa altimétrica entre 660 e 120 metros (correspondente ao quilômetro 8 ao 22), relacionada à porção em subsidência do perfil, nota-se a continuidade de alta energia do gradiente do rio. A área homônima insere-se entre os trechos 20 e 46 e associa-se ao compartimento geomorfológico Contrafortes da Serra Geral.

Nesta porção do perfil longitudinal também se localizam trechos com contínuas rupturas de declive, todavia, diferentemente do setor anterior, este segmento do rio caracteriza-se por forte controle estrutural. As anomalias identificadas inserem-se nos limiares de $1^{\text {a }}$ ordem e alojam-se nas descontinuidades que limitam a Formação Botucatu e Formação Gramado. Observam-se tais deformações a partir dos picos da linha do incide SL entre os contatos litológicos. Portanto, observa-se forte controle estrutural neste setor, capaz de direcionar o rio por entre as falhas e fraturas litológicas identificadas. Linhas de fraqueza correlacionadas a retomadas erosivas da escarpa do planalto.

A faixa altimétrica entre 120 e 20 metros (correspondente ao quilômetro 22 ao 48), correlaciona-se ao setor de transição dos trechos em subsidência para o estado agradacional. Verifica-se a diminuição do gradiente assim como do poder erosivo dos trechos, em compensação, percebe-se nítido aumento da capacidade deposicional do rio. A área homônima insere-se entre os trechos 47 a 51 e caracteriza-se pela disposição de leques aluviais sobre o conjunto de morros e colinas que se estendem no compartimento da Planície Costeira. Presenciam-se neste setor, anomalias de $1^{\mathrm{a}}$ ordem $(15,08$ a 25,88$)$, associadas às desembocaduras de tributários volumosos nesta porção do rio.

$\mathrm{Na}$ faixa altimétrica entre 20 e 0 metros (correspondente ao quilômetro 48 ao 108) o gradiente se suaviza, a incisão do talvegue diminui e o rio Araranguá passa a percorrer planícies alargadas até a foz. A porção do perfil homônima refere-se ao trecho 52, o qual apresenta anomalias de $2^{\mathrm{a}}$ ordem, possivelmente 
relacionadas às desembocaduras de tributários menos volumosos, visto que os valores do índice são menores e o porte dos afluentes também.

Observa-se que estre trecho corresponde a maior extensão em relação à equidistância de 20 em 20 metros, representando $59,75 \mathrm{~km}$ da totalidade do rio. Estes números evidenciam relativo equilíbrio no baixo curso, porém salienta-se ambiente de agradação. Nestas planícies observa-se a espacialização de superfícies aplainadas, recobertas por coberturas superficiais, com patamares escalonados em direção ao curso d'água e/ou oceano Atlântico. Estas formas constituem os baixos terraços marinhos, flúviomarinhos, flúviolacustres e fluviais. Tais paleoregistros geomorfológicos possuem gênese atrelada a movimentos eustáticos, promovidos por pulsações climáticas holocênicas, que recentemente (tempo geológico) podem ter depositados espessos mantos de depósitos marinhos na foz do rio em episódios regressivos.

De acordo com a aplicação dos índices no perfil longitudinal, o rio Araranguá, possui 48 trechos com anomalias de $1^{\mathrm{a}}$ ordem $(92,3 \%), 3$ trechos com anomalias de $2^{\mathrm{a}}$ ordem $(5,7 \%)$ e apenas um trecho em relativo equilíbrio (2\%). Entretanto, salienta-se para a extensão do rio a qual estas anomalias se associam. Os setores anômalos de $1^{\text {a }}$ ordem estão espacializadas ao longo de $42 \mathrm{~km}$, e representam 38,9\% da totalidade (108 km de extensão do rio Araranguá); as anomalias de $2^{\mathrm{a}}$ ordem estão distribuídas ao longo de $64 \mathrm{~km}$, representando $59,3 \%$ da extensão total do rio; os trechos em equilíbrio atuam em $2 \mathrm{~km}$ do curso d'água, próximo a cabeceira e, representam 1,8\% em relação a extensão total do rio.

Estes dados são úteis para alertar possíveis interpretações equivocadas sobre a disposição das anomalias. Nota-se que ao alterar o enfoque da análise, as proporções de atuações se alteram. Ao verificar quantitativamente os trechos anômalos, obtêm-se informações que erroneamente associam um predomínio das anomalias de $1^{\text {a }}$ ordem na extensão do perfil, quando na realidade o predomínio relaciona-se as anomalias de $2^{\mathrm{a}}$ ordem, dispostas em $64 \mathrm{~km}$ do rio (59,3\% da extensão total).

\section{Considerações finais}

A morfologia do perfil longitudinal do rio indica trechos de soerguimento no alto curso, relacionados a eventos tectônicos deformacionais que se associam as maiores anomalias verificadas ( $1^{\mathrm{a}}$ ordem).

Ainda no alto curso, extendendo-se em direção à parte final do médio curso, observa-se consideravel trecho do perfil em subsidência, relacionado à forte controle estrutural, onde, as anomalias identificadas ( $1^{\text {a }}$ ordem) alojam-se nas fraturas, falhas e descontinuidades que limitam a Formação Botucatu e Formação Gramado.

Ao fim do médio e ao longo de todo baixo curso, nota-se zona agradacional relacionada à atuação de diferentes sistemas deposicionais (marinho, eólico, lagunar e fluvial), que em conjunto originam superfícies planas com declives suaves, marcadas por poucas anomalias de $1^{\mathrm{a}}$ e $2^{\mathrm{a}}$ ordem, associadas às 
desembocaduras de tributários volumosos relacionados aos trechos anômalos de $1^{\text {a }}$ ordem e afluentes menos expressivos correlacionados a anomalias de $2^{\mathrm{a}}$ ordem.

Constatou-se, baseado em Schumm (1993), que a rede de drenagem constitui-se como importante elemento geomorfológico, suscetível a alterações do substrato geológico, deflagrando anomalias que podem oferecer subsídios para interpretação da evolução da paisagem pautada na influência morfoestrutural e morfotectônica.

A elaboração do Perfil Longitudinal e aplicação do índice SL de Hack (1973) apresentaram-se essenciais para identificação de anomalias, representadas por ressaltos convexos no perfil, correlacionadas a deformações crustais, controles estruturais e desembocaduras de tributários.

\section{Agradecimentos}

Externamos nossos agradecimentos à Fundação de Amparo à Pesquisa do Estado de São Paulo (FAPESP), pelo fomento financeiro da pesquisa por meio do Processo 2016/05327-6 e 2016/08944-6.

\section{Bibliografia}

ADAMI, R. M.; CUNHA, Y. M. Plano de Recursos Hídricos da Bacia do rio Araranguá: Fase A. Criciúma: Comitê do Araranguá, Projeto Piava Sul, 2011, 198p.

BISHOP, P. Stream profile change and longterm landscape evolution: early Miocene and modern rivers of the east Australian highland crest, central New South Wales, Australia. Journal of Geology, v. 93, p. 455-474, 1985.

CAMOLEZI, B. A.; FORTES, E.; MANIERI, D. D.Controle estrutural da rede de drenagem com base na correlação de dados morfométricos e morfoestruturais: o caso da bacia do Ribeirão São Pedro - Paraná. Revista Brasileira de Geomorfologia, v.13, n.2, p.201-211, 2012.

COUTO, E. V.; FORTES, E.; FERREIRA, J. H. D.; Índices geomorfológicos aplicados a análise morfoestrutural da zona de falha do rio Alonzo - PR. Revista Brasileira de Geomorfologia, v.14, n.4, p.287-297, 2013.

DANTAS, M. E.; GOULART, D. R.; JACQUES, P. D.; ALMEIDA, I. S.; KREBS, A. S. J. Geomorfologia aplicada à gestão integrada de bacias de drenagem: bacia do rio Araranguá (SC), zona carbonífera sul-catarinense. In: SIMPÓSIO BRASILEIRO DE RECURSOS HÍDRICOS, 16.,. 2005, João Pessoa, PB., Anais... João Pessoa, PB: ABRH, 2005. 74p. CD Rom.

ETCHEBEHERE, M. L.; SAAD, A. R.; FULFARO, V. J.; PERINOTTO, J. A. J.; Aplicação do Índice Relação Declividade-Extensão Geol. USP Sér. Cient., São Paulo, v.4, n.2, p.43-56, 2004.

GUEDES, I. C.; SANTONI, G. C.; ETCHEBEHERE, M. L.; STEVAUX, J. C.; MORALES, N.; SAAD, A. R. Análise de perfis longitudinais de drenagens da bacia do rio Santo Anastácio (SP) para detecção de possíveis deformações neotectônicas. Revista UnG - Geociências, v.5, n.1, p.75-102, 2006.

HACK, J. T. Stream-profile analysis and stream-gradient index. Journal of Research of the United States Geological Survey, v.1, n. 4, p. 421-429, 1973.

HORTON, R. E. Erosional development of streams and their drainage basins: hydrophysical approach to quantitative morphology. Geological Society of America Bulletin, v. 56, p. 275-370, 1945.

PHILLIPS, L. F.; SCHUMM, S. A. Effect of regional slope on drainage networks. Geology, v. 15, p. 813-816, 1987.

SCHUMM, S. A. River response to baselevel change: Implications for sequence stratigraphy. Journal of Geology, v. 101, p. 279-294, 1993. 


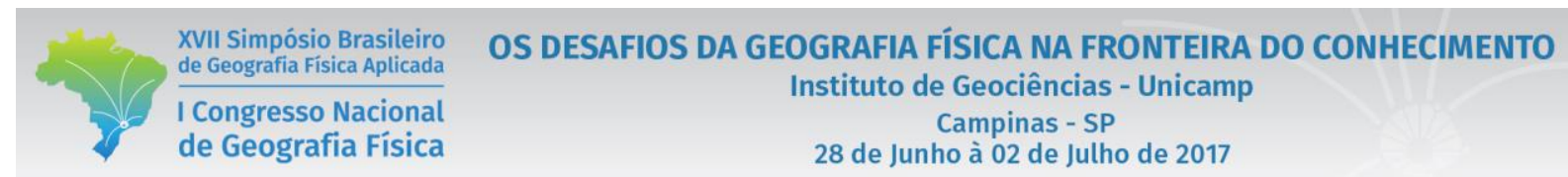

SEEBER, L.; GORNITZ, V. River profiles along the Himalayan arc as indicators of active tectonics. Tectonophysics, v. 92, p. 335-367, 1983.

STRAHLER, A. N. Dynamic basis of geomorphology. Geological Society of American Bulletin, v. 63, p. 923-938, 1952

MARQUES NETO, R.; PEREZ FILHO, A. Análise morfoestrutural e morfotectônica da bacia do rio Capivari, sul de Minas Gerais: a neotectônica e as superfícies geomorfológicas. Revista Brasileira de Geomorfologia, v.14, n.4, p.271-277, 2013.

PINHEIRO, M. R.; QUEIROZ NETO, J. P. Neotectônica e evolução do relevo da região da serra de São Pedro e do baixo rio Piracicaba/Sudeste do Brasil. Revista Brasileira de Geomorfologia, São Paulo, v.16, n.4, p.593-613, 2015. 